\title{
Papers
}

\section{Nutritional status and mortality of refugee and resident children in a non-camp setting during conflict: follow up study in Guinea-Bissau}

\author{
Peter Aaby, Joaquim Gomes, Manuel Fernandes, Queba Djana, Ida Lisse, Henrik Jensen
}

\begin{abstract}
Objective To study the effects on children of humanitarian aid agencies restricting help to refugee families (internally displaced people).

Design Follow up study of 3 months.

Setting Prabis peninsular outside Bissau, the capital of Guinea-Bissau, which has functioned as a refugee area for internally displaced people in the ongoing war, and the study area of the Bandim health project in Bissau.

Participants 422 children aged 9-23 months in 30 clusters.

Main outcome measures Mid-upper arm circumference and survival in relation to residence status.

Results During the refugee situation all children deteriorated nutritionally, and mortality was high (3.0\% in a 6 week period). Rice consumption was higher in families resident in Prabis than in refugees from Bissau but there was no difference in food expenditure. Nutritional status, measured by midupper arm circumference, was not associated with rice consumption levels in the family, and the decline in circumference was significantly worse for resident than for refugee children; the mid-upper arm circumference of refugee children increased faster than that of resident children. For resident children, mortality was 4.5 times higher $(95 \%$ confidence interval 1.1 to 30.0 ) than for refugee children. Mortality for both resident and refugee children was 7.2 times higher (1.3 to 133.9) during the refugee's stay in Prabis compared with the period after the departure of the refugees.

Conclusion In a non-camp setting, residents may be more malnourished and have higher mortality than refugees. Major improvements in nutritional status and a reduction in mortality occurred in resident and refugee children as soon as refugees returned home despite the fact that there was no improvement in food availability.
\end{abstract}

\section{Introduction}

Distribution of humanitarian aid among poor populations may have major implications for health-directly, by providing needed nutrients and indirectly, by affect- ing people's social behaviour and patterns of movement, which in turn may affect morbidity and mortality. In emergency situations it may therefore be critical how social groups are categorised and prioritised by humanitarian aid agencies.

The health of refugees and displaced people has been mainly studied in camp settings, ${ }^{1-3}$ and in this context has strongly influenced the way such people are treated. For example, during the current crisis in Guinea-Bissau, ${ }^{4}$ the international emergency agencies, the World Food Programme and the International Committee for the Red Cross, restricted food aid to the estimated 350000 refugees (internally displaced people). This was thought both unjust and unjustified by Guineans and local expatriates concerned with humanitarian aid. In the Guinean crisis, there have been no camps $^{1}$; all refugees have lived with either relatives, friends, or strangers, and utilised their resources. Both resident hosts and refugees felt that they were entitled to receive any help available. Since the policies of international and local organisations represent very different understandings of the implications of the displacement of people, and since there has been little research on the consequences of non-camp settings, we examined health outcomes for both refugee and resident children.

\section{Background}

The war

On 7 June 1998, armed conflict started in GuineaBissau between rebel soldiers (military junta) and the government army, which 3 days later received the support of troops from neighbouring countries Senegal and Guinea. Initially the rebels made no attempt to stage a coup d'état but took certain military camps and demanded negotiations with the president. The government had dismissed the commander in chief of the armed forces on charges of alleged involvement in selling of arms to the rebels in Senegal, although a committee report debated in the national assembly on 9 June implicated the president's men and not the commander in chief. The arrival of the foreign troops provoked a fully fledged war. During the first week of the conflict, the foreign troops set up cannons in the most populated districts of the capital, Bissau, behind churches and hospitals, and in response the city was
Department of
Epidemiology
Research, Danish
Epidemiology
Science Centre,
Statens Serum
Institut, 2300
Copenhagen S,
Denmark
Peter Aaby
anthropologist
Bandim Health
Project, Bissau,
Guinea-Bissau
Joaquim Gomes
field supervisor
Manuel Fernandes
field supervisor
Queba Djana
field supervisor
Ida Lisse
consultant
Henrik Jensen
statistician
Correspondence to:
P Aaby paa@ssi.dk 


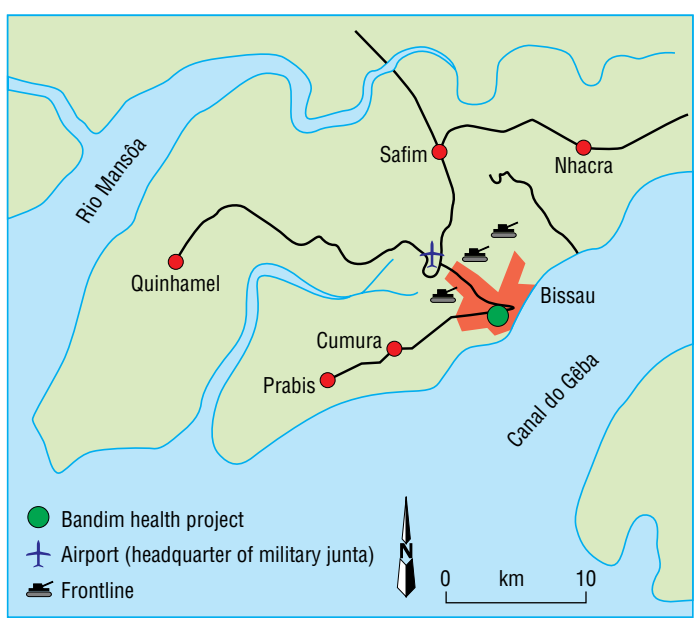

Area surrounding Bissau, 1998: during the war major battles occurred along the road to the airport (the only road to the interior of Guinea-Bissau). Government and foreign troops had heavy artillery positions in the centre of the city, whereas rebel artillery was placed around the airport and at Cumuré, south of Nhacra. Cars could only leave towards mission station in Cumura and the village of Prabis, two areas with major concentrations of refugees in Bissau. Exit from Prabis area was only possible by canoe to Bijagos islands or by crossing the river to Quinhame

shelled heavily by rebel artillery. The revolt quickly turned into an ideological war, with more than $90 \%$ of the armed forces and most veterans from the liberation struggle (1963-74) joining the fight against a corrupt president and the foreign troops. When the national assembly finally met in November 1998, the members voted that the president should leave office: he failed to do so.

\section{Mass exodus}

Nearly all 300000 inhabitants of Bissau had fled the city by mid-June, leaving behind a mere 10000 government officials, troops, owners defending their property, elderly people not wanting to leave, and opportunistic thieves. Around 50000 of the fleeing people took refuge just $5-15 \mathrm{~km}$ outside Bissau in the villages on the Prabis peninsular (figure), an area that before the war had an estimated population of $6858 .{ }^{4}$ During the most intensive fighting, houses in Prabis had on average more than 100 inhabitants when both relatives and foreigners moved in to live with the owners. Many more people fled through Prabis (the only route for cars from Bissau), en route for the Bijagos islands or the interior by canoe. During this period Prabis remained under government control whereas most of the interior was under rebel control. The first part of the war lasted from 7 June until the end of July, a ceasefire being agreed on 26 July. As soon as the fighting stopped, refugees from the Prabis area started returning to Bissau; virtually all refugees had left by the end of August.

\section{Food distribution}

The first relief activity implemented by national health authorities was rice distribution from the World Food Programme's store in Bissau. To evaluate the coverage for food distribution and to assess the need for other actions, we began surveying, in the first week of July after 3 weeks of conflict, children aged 9-23 months to assess vaccination status, ${ }^{4}$ mid-upper arm circumfer- ence, and their family's rice consumption, food expenditures, and receipt of food aid.

\section{Participants and methods}

\section{Surveillance}

Using a census carried out as a basis for distribution of food in the Prabis area, we randomly selected 30 clusters, each with 14 children aged 9-23 months. ${ }^{4}$ Communities included in the study were placed on a list with sequential numbers indicating, for example, that village A had the 110th to the 985th individual in the area. The distance (D) between clusters was calculated as $1 / 30$ of the total number of individuals in the area $(\mathrm{N})$. A random number $(\mathrm{X})$ was selected between 1 and N/30. The first cluster was selected in the community that had the Xth individuals and subsequent clusters in the communities that had the $(\mathrm{X}+\mathrm{nD})$ th individuals, $\mathrm{n}$ being a number between 1 and 29. Within a community, we examined all children aged 9-23 months in house number $\mathrm{H}$ having the $\mathrm{Xth}$ individual. If there were fewer than 14 children in the house, we proceeded to include children from house number $\mathrm{H}+1$, etc. If the 14 th child in a cluster lived in a house with several children in the correct age group, all of the children were included.

Of the 422 children included in our survey, 104 $(25 \%)$ were residents in the Prabis area before the conflict; of the remaining 318 refugee children, 41\% (130) were from the area normally covered by the Bandim health project ${ }^{5}$ and could be identified in the project's register, which included information on date of birth, birth history, breast feeding, vaccinations, infectious diseases, and arm circumference.

We visited all the children again 3, 6, 9, and 12 weeks later, until the last week of September. The first three visits were only conducted in Prabis. At the last two visits, however, we also carried out examinations in the four districts of the project area in Bissau-Bandim 1, Bandim 2, Belem, and Mindará-because most refugees had already returned to these areas. At each visit, we measured mid-upper arm circumference to the nearest $2 \mathrm{~mm}$ with an insertion tape.

\section{Reference populations}

To assess whether mid-upper arm circumferences had decreased during the war, we compared measurements taken from refugees during the war with those taken in July 1997 from children in Bandim, Belem, and Mindará aged 9-23 months. Prabis children were compared with children of the same age group who also had been examined in July 1997 in a survey of 20 clusters of children from the Biombo region, of which Prabis is a part. ${ }^{6}$

To examine whether the refugee children in Prabis were any different from the children from the study area, we analysed the arm circumferences, measured between March and May 1998, of children who survived to July 1998 and who were 9-23 months old in July 1998 in relation to whether they were later examined in Prabis or not.

\section{Death ascertainment}

Even if children were not seen at follow up visits, we inquired about their survival and whereabouts. A 
Crude prevalence of arm circumference $<130 \mathrm{~mm}$ and mean rice consumption, food expenses, and upper arm circumference according to residence status in Prabis, Guinea-Bissau. Values are percentages (numbers) of children unless stated otherwise

\begin{tabular}{|c|c|c|c|c|c|}
\hline \multirow[b]{2}{*}{ Variable } & \multicolumn{5}{|c|}{ Visit* } \\
\hline & 1 & 2 & 3 & 4 & 5 \\
\hline \multicolumn{6}{|l|}{ Low arm circumference $(<130 \mathrm{~mm})$} \\
\hline Residents & $24(23 / 97)$ & $29(28 / 97)$ & $33(26 / 79)$ & $27(21 / 77)$ & $17(13 / 78)$ \\
\hline \multicolumn{6}{|l|}{ Refugees: } \\
\hline Non-project & $15(27 / 178)$ & $18(24 / 133)$ & $22(11 / 50)$ & $17(3 / 18)$ & $12(2 / 17)$ \\
\hline Project† & $12(14 / 121)$ & $18(18 / 99)$ & $0(0 / 19)$ & $15(16 / 108)$ & $7(8 / 109)$ \\
\hline \multicolumn{6}{|c|}{ Mean rice consumption (g per family member per day) } \\
\hline Residents & $546(96)$ & $523(95)$ & $524(75)$ & $527(75)$ & $539(65)$ \\
\hline Refugees & $450(114)$ & $472(96)$ & $510(19)$ & $380(105)$ & $372(104)$ \\
\hline \multicolumn{6}{|c|}{ Mean additional expenditure (CFA‡ per family member per day) } \\
\hline Residents & $191(93)$ & $216(93)$ & $211(74)$ & $199(75)$ & $244(72)$ \\
\hline Refugees & $232(112)$ & $187(94)$ & $170(19)$ & $194(104)$ & $192(108)$ \\
\hline \multicolumn{6}{|l|}{ Mean mid-upper arm circumference $(\mathrm{mm})$} \\
\hline Residents & $139(97)$ & $135(97)$ & $135(79)$ & $136(77)$ & $139(78)$ \\
\hline Refugees (project†) & $142(121)$ & $140(99)$ & $142(19)$ & $143(108)$ & $143(109)$ \\
\hline Growth $(\mathrm{mm})$ for residents $v$ refugees $(95 \% \mathrm{Cl}) \S$ & & $-1.7(-3.6$ to 0.1$)$ & $-4.9(-8.0$ to -1.8$)$ & $-3.6(-5.9$ to -1.3$)$ & $-1.2(-3.6$ to 1.2$)$ \\
\hline
\end{tabular}

trained assistant conducted interviews with relatives of all deceased children to obtain a description of symptoms at death and to verify the quality of the death ascertainment; one child initially classed as dead had not died but had been confused with an older sibling who had died.

\section{Food consumption and distribution}

We recorded the number of people in the household and whether they had received food aid within the past 3 weeks. The Guinean staple is rice, and it is possible to estimate the daily household consumption of rice as it is always measured with tins of $0.5 \mathrm{~kg}$ or $1 \mathrm{~kg}$ capacity. We estimated additional daily food expenditures as the amount of money available for buying items at the market such as fish, meat, oil, tomatoes, onions, limes, green leaves, aromatic cubes, salt, and charcoal for cooking.

Refugees had only taken small quantities of rice with them when they fled, and food distribution was therefore started at the end of June. In the first round of food distribution for the refugees, the Red Cross provided $25 \mathrm{~kg}$ of rice, 8 litres of cooking oil, and $6 \mathrm{~kg}$ of corned beef per household for the first week. As there was no time to organise distribution according to the number of people in a family, an average household was assumed to comprise eight people. The $3 \mathrm{~kg}$ of rice per person per week was estimated on the basis of a recommended minimum consumption of $400 \mathrm{~g}$ of cereal per person per day. As the first distribution of rice in the Prabis area took 3 weeks, it was effectively a ration of only $133 \mathrm{~g}$ per person per week. In the second and third round of distribution in July and August, managed by the Bandim health project, households received food allowances according to the actual number of people in the household, and the ration of rice was gradually reduced to one third and one fifth of daily needs - that is, $133 \mathrm{~g}$ and $80 \mathrm{~g}$ respectively-owing to the expected shortage of foodstuffs for humanitarian aid. After the ceasefire on 26 July, the refugees started to return to Bissau, and food distribution was stopped in Prabis. Food distribution continued in the project area in Bissau from the end of August, providing a daily allowance of $100 \mathrm{~g}$ of rice for a 3 week period-that is, $2 \mathrm{~kg}$ per person. We managed to distribute only in three of the four districts in the area because the World Food Programme's food stock was depleted by the first week of September.

\section{Statistical methods}

Because the children were measured several times, it was necessary for us to adjust for correlation between repeated observations. We used a general linear model for longitudinal data and a mixed model to account for repeated measurements of the same individual and to adjust for different background factors. ${ }^{7}$ We also controlled for cluster design by including the cluster variable as a factor in the mixed model. Age and sex were controlled in the analysis of arm circumference. We used a paired $t$ test to analyse expenditure. Comparisons of mortality were adjusted for age (6-11, 12-17, and 18-32 months). We used Poisson regression to analyse mortality. Calculations were carried out with sAs for Windows (release 6.12).

\section{Results}

Visits to the children

At the first visit at the beginning of July, we measured the arm circumference of $94 \%(396 / 422)$ of the children (table). At the second visit, we examined $79 \%$ (329/416) of the survivors; at the third visit, a ceasefire had been established, and most children had returned to Bissau, with only $36 \%$ (148/409) of the survivors being re-examined in Prabis. At the fourth and fifth visits, conducted in both Prabis and Bissau, we examined 50\% (203/409) and 50\% (204/408) of the children respectively, and $82 \%(185 / 226)$ and $83 \%$ $(187 / 225)$ of the children who could be followed most easily-that is, those who were resident in the Prabis area or who were registered in the project area in Bissau before the war. In the further analyses, we therefore 
gave priority to the resident and refugee children from the project area.

\section{Mid-upper arm circumference}

At the first examination we found a major difference in the prevalence of mid-upper arm circumference measurements of less than $130 \mathrm{~mm}$ (low arm circumference) between refugee and resident children (table). This difference may have been influenced by the war; in the reference population of children examined in July 1997 , the prevalence was $11 \%(66 / 626)$ in refugee children but 19\% (38/202) in resident children (from the Biombo region). We found no difference in mean arm circumference between the refugee children in Prabis and those from the study area: $143.4 \mathrm{~mm} v$ $143.7 \mathrm{~mm}$, respectively, for 79 of 130 children from the study area who were measured between March and May, and 1047 other children in Bissau who were not measured in Prabis.

\section{Food consumption}

In the first round of food distribution carried out by the Red Cross in June 1998, a higher proportion of refugee families $(41 \%, 123 / 299)$ than resident families $(16 \%, 16 / 99)$ received food aid (relative risk 2.6, 95\% confidence interval 1.6 to 4.0 ). In subsequent distributions organised by the Bandim health project, there was no difference for refugee children $(87 \%, 85 / 98)$ and resident children $(91 \%, 243 / 267)$ in coverage (1.1, 0.96 to 1.2). Rice consumption patterns were different for residents and refugees during the 3 months (table). The members of resident households clearly had more rice available than members of refugee families from Bissau $(\mathrm{P}<0.001)$, but there was no systematic difference in availability of money for purchasing additional foodstuff. Rice consumption for residents remained comparatively stable over time, decreasing by only $8 \mathrm{~g}(95 \%$ confidence interval -35 to 52$)$ from the first to fifth visit; for refugees, consumption changed when they got back to Bissau, showing a reduction of $76 \mathrm{~g}$ (36 to 116) from the first to fifth visit, controlled for cluster and repeated observations. Daily expenditure per person tended to increase for resident families between the first and fifth visit (48 CFA (100 CFA is equivalent to $£ 0.10$ ), -3 to 98 ) and to decrease for refugee families (41 CFA, 10 to $73 ; \mathrm{P}=0.004$ ).

\section{Mid-upper arm circumference versus food consumption}

Although the children should have grown during the period of observation, there was a significant decline in mid-upper arm circumference for both resident and refugee children, the decline being stronger for resident than for refugee children (table). In a mixed model controlling for age, sex, cluster, and repeated measurements, the profiles for mid-upper arm circumference were significantly different (test of interaction: $\mathrm{P}=0.003$ ). Increases in mid-upper arm circumference started when the refugee children returned to Bissau and occurred later among resident children (fifth visit) than refugee children (fourth visit). In the same model, there was no association between mid-upper arm circumference and family rice consumption $(\mathrm{P}=0.9)$. Daily expenditures for food per person (classed as 0 , 1-100, 101-200, 201-300, $\geqslant 301$ CFA) were positively related to higher values for mid-upper arm circumfer- ence but were not different for resident and refugee children (test of interaction: $\mathrm{P}=0.6$ ).

\section{Mortality}

Over the 3 month period, the 104 resident children had a significantly higher mortality (seven deaths) than the 130 project children from Bissau (two deaths; mortality ratio $4.5,1.1$ to 30.0 ). Mortality was also much higher for resident and refugee children in the 6 weeks while refugees were in Prabis (eight deaths) compared with the last 6 weeks when the refugees had left (one death; $7.2,1.3$ to 133.9). These estimates were adjusted for age but not for cluster as data were sparse. All nine deaths occurred in different clusters. Further adjustment for arm circumference had only a minor impact on the difference between resident and refugee children (3.8, 0.9 to 25.9$)$ and no impact on the period effect (7.4, 1.3 to 138.1).

\section{Discussion}

\section{Consequences of displacement}

In the non-camp setting during the Guinean crisis, resident children aged 9-23 months suffered more than refugee children from Bissau; this age group is the most vulnerable to malnutrition, infections, and mortality. The resident children were marginally worse off initially for nutritional status (table) but growth was worse for the residents even allowing for these initial differences and the cluster design. Hence, population displacement may have consequences for a wider group of people than is usually considered. ${ }^{23} \mathrm{~A}$ profound improvement in nutritional status and mortality occurred among both refugees and resident children once the refugees had left. The children coped better in their normal environment even though the rice consumption of refugee families decreased when they returned to Bissau.

In the present crisis, there has been no major deficiency in rice consumption for the population of Prabis. It was only after the refugees returned to Bissau that the average reported rice consumption decreased below the recommended daily consumption. Only a minor proportion of the rice consumption can be ascribed to food aid which did not contribute more than 50-150 g per person per day throughout the period. Rice availability was influenced by the military junta "liberating" a major rice warehouse; consequently, the price of rice dropped to $20 \%$ below prewar levels in the refugee area during July.

No direct connection was found between household rice consumption and nutritional status of young children in a situation without hunger and starvation. Nutritional status declined while consumption levels were maintained and improved while family consumption decreased. This should not be too surprising in a society where virtually all children under 2 years of age are still breast fed and consume specially prepared porridges. It is therefore also unlikely that general food distribution will have a profound effect on childhood survival, and in our study we found no relation between receipt of food aid and nutritional status or survival.

Nutritional status seems more likely to be related to morbidity; exposure to infections and lack of treatment may be more important determinants of morbidity and mortality. With the extreme crowding ${ }^{8}$ and 
unhygienic conditions that existed for the refugees in Prabis, it is not surprising that mortality was much higher for both residents and refugees while living under refugee conditions.

No simple explanation can explain why resident people were affected more than refugees. Refugee families are unlikely to have been a particularly privileged group as the Bissau children registered in Prabis were not different from other children from the study area before the war. Furthermore, resident families seem to have been better off in terms of rice availability, and there was no difference in expenditures for food consumption. We found no difference in measles immunisation between refugees and resident children (data not shown). ${ }^{4}$ Duration of breast feeding differs little between urban and rural populations in GuineaBissau, although it might last longer in rural areas such as Prabis. Nutritional status is normally better in urban than rural areas, but the difference registered in July (table) was larger than usual, presumably reflecting that differential growth had already occurred during the first weeks of the war. As the first measurements of mid-upper arm circumference in July may have been already affected by differential growth, it is questionable whether adjustment for arm circumference is justified in the mortality analysis. The differential growth and mortality is presumably related to differences in health and treatment practices and in disease exposure. Resident children may have been more intensively exposed and exposed for a longer period because of their prolonged proximity to refugee children.

\section{Movement of refugees}

Child mortality was much lower once refugee families had returned to their homes. The question of residence was, however, complicated because the military junta recommended that refugees stay away from Bissau, which was controlled by foreign troops, to retain the option of shelling the city during renewed armed conflict. Although the population was in favour of the military junta, most refugees returned to the city once a ceasefire had been arranged to protect their belongings (theft was rampant) and to live under more comfortable conditions than in Prabis; $84 \%$ of the registered population from the study area had returned to Bissau by mid-September. Food distributions also affected refugees' travelling patterns-for example, many people remained in the Prabis area to receive the expected food aid and we were effectively delaying their return by continuing to distribute in this area. In mid-August we transferred food distribution to Bissau to prevent people from continuing to live under unhealthy conditions. However, the World Food Programme, which has been the main agency supplying food aid to Guinea-Bissau during the present crisis, continued to distribute in the interior of the country. The organisation had no idea that most of the refugees were back in Bissau by the end of August. Furthermore, United Nations safety regulations did not permit UN employees to stay in Bissau, making it more convenient to continue the operation in the interior of the country. In the project area in Bissau, all refugees who had gone to Prabis had returned by the end of August, whereas many of those who had gone to
Key messages

- During the war in Guinea-Bissau, most of the population fled from the capital and moved in with relatives, friends, or strangers

- International agencies insisted on only providing help to refugees (internally displaced people)

- During the first month of conflict, there were already profound effects on the nutritional status and mortality of young children

- Food consumption was higher in resident families, but resident children were more malnourished and had higher mortality than refugee children

- Nutritional status and survival improved for both refugee and resident children once the refugees returned to Bissau

areas where the World Food Programme continued its distribution had yet to return by October.

The major observations of our study were the profound effects on the health of residents housing refugees and the improvement once the refugees had left. Refugees and displaced people have been mainly studied in camp settings where effects may be different. Non-camp settings are, however, probably common in the early phases of emergencies before international agencies organise their programmes. Whether residents or refugees are affected most may depend on local circumstances and conditions before the events leading to displacement. In non-camp settings, however, displacement is likely to lead to increased crowding and deterioration in hygiene and, consequently, to increased morbidity and mortality for both residents and refugees. The international agencies were clearly unaware of this possibility: they insisted on distributing aid only to refugees. It seems important also that concentrations of displaced people should be dispersed as quickly as possible. The most important consequences of general food distribution in an emergency situation may therefore not be the direct impact on nutritional levels but the indirect effects on movements and social behaviour, which have important consequences on exposure to disease. This requires humanitarian agencies to be aware of movement patterns and to be capable of following the population rather than vice versa.

In the discussion between international agencies and local organisations about distribution policy, both may have been right and wrong. Resident families had better food security but they also had more severe health outcomes. There is little doubt that equal distribution would have made the most sense for minimising conflicts between the groups. Adverse health consequences should, however, probably have been countered with disease specific preventive action rather than more food distribution.

After the completion of our study, the population of Bissau has been on the move again after violations of the ceasefire and general fighting between the foreign troops and military junta in both October 1998 and January 1999. 
Contributors: PA and IL planned the study. JG, MF, and QD organised and supervised data collection and food distribution. HJ carried out the statistical analyses. PA drafted the first version of the paper, and all authors contributed to the final version. PA and $\mathrm{HJ}$ will act as guarantors for the paper.

Funding: The Bandim health project received support for research from the Danish International Development Agency, the Danish Council for Development Research, and the Danish Medical Research Council (SSVF 9700560); the Science and Technology for Development Programme of the European Community (TS3*CT91*0002 and ERBIC 18 CT95*0011); and UNICEF, Guinea-Bissau. Relief work was funded by the Swedish Embassy, Guinea-Bissau.

Competing interests: None declared.

1 Van Damme W. Do refugees belong in camps? Experiences from Goma and Guinea. Lancet 1995;346:360-2
2 Toole MJ, Waldman RJ. Prevention of excess mortality in refugee and displaced populations in developing countries. JAMA 1990;263:3296-302.

3 Van Damme W, De Brouwere V, Boelaert M, van Lerberghe W. Effects of a refugee-assistance programme on host population in Guinea as measured by obstetric interventions. Lancet 1998:351:1609-13.

4 Aaby P, Martins C, Balé C, Lisse I. Assessing measles vaccination coverage by maternal recall in Guinea-Bissau. Lancet 1998;352:1229.

5 Aaby P. Bandim: an unplanned longitudinal study. In: Das Gupta M, Aaby P, Pison G, Garenne M, eds. Prospective community studies in developing countries. Oxford: Clarendon, 1997:276-96.

6 Aaby P, Gomes J, Høj JL, Sandström A. Estudo de saúde de mulheres em idade fertil e os seus filhos.Dados de 1990-1995. Bissau: Projecto de Saúde de Bandim, 1997.

7 Diggle PJ, Liang K-Y, Zeger SL. Analysis of longitudinal data. New York: Oxford University Press, 1994

8 Aaby P, Bukh J, Lisse IM, Smits AJ. Overcrowding and intensive exposure as determinants of measles mortality. Am J Epidemiol 1984;120:49-63.

(Accepted 12 May 1999)

Cite this article as:

Aaby P, Gomes J, Fernandes M, Djana Q, Lisse I,

Jensen $\mathrm{H}$. Nutritional status and mortality of refugee and resident children in a non-camp setting during conflict: follow up study in Guinea-Bissau [abridged version]. $B M$ J 1999;319:878-81.(full version: www.bmj.com/cgi/ content/full/319/7214/878) 